
Georg Reimer

Verlag
Berlin W. 35,

Latzowstrasse 107/8.

\section{Zur Vertheidigung}

der

\section{Organischen Methode}

in der

\section{Sociologie}

von

Paul von Lilienfeld.

= Preis broschirt Mk. 1.20. $\equiv$

.. Durch diese wenigen Sätze sei ein Begriff von des Verfassers organischer Methode gegeben. Seine Ḱonsequenz und Gewandtheit in der Durehführung und Vertheidigung der Gesellschaft als eines lebendigen Organismus, als eimes Individuums ist anzuerkennen und wird nicht ohne Eindruck bleiben, da man jetzt überall, besonders aber in der Ethnologie, vơn der Ueberzeugung durchdrungen ist, wio der Einzelne in jeder Beziehung nur als Glied der Gesellschaft zu verstehen ist.

Zeitachrift für Antbropologie. 


\title{
Gedanken
}

\author{
über die \\ Socialwissenschaft \\ der Zukunft \\ von
}

Paul von Lilienfeld.

I. Theil:

Die menschliche Gesellschaft als realer Organismus.

Mitau 1873.

In Commission bei Georg Reimer.

Berlin 1901. 
D i e

\section{menschliche Gesellschaft}

als

realer 0rganismus

Von

Paul von Lilienfeld.

Mitau 1873.

In Commission bei (ieorg Reimer.

Berlin 1901. 